\title{
Editorial: Intelligent Learning Systems in Banking and Finance
}

\author{
Vincenzo Pacelli* \\ Faculty of Economics, University of Foggia, Foggia, Italy. \\ Email: v.pacelli@unifg.it
}

Received July $10^{\text {th }}$, 2010; revised October $1^{\text {st }}, 2010$; accepted December $1^{\text {st }}, 2010$.

The non-linear and often obscure relations that govern the economic and financial variables, the presence of significant amounts of data and the failures of the conventional mathematical and statistical models are only some reasons which should encouraged a growing development of the studies on the application of the intelligent learning systems in banking and finance.

The literature on the application of artificial intelligence systems (such as neural networks, expert systems, fuzzy models and genetic algorithms) to the fields of banking and finance has explored various aspects, which can be classified according to the following taxonomy in four macro-categories:

1) studies on the application of these models on time series forecasting;

2) studies on the application of these systems within the classification and discrimination of economic phenomena, with particular attention to the management of credit risk;

3) studies on the application of these systems within the approximation of economics function, with particular attention to the phenomenon of pricing of financial products;

4) studies on the application of these models on the portfolio management, with a particular focus on the portfolio optimization.

The purpose of this special issue of the JILSA is to analyze the role of the intelligent learning systems and algorithms in banking and finance, both in a theoretical and empirical point of view.

All papers went through a rigorous peer review procedure and each paper received at least three review reports. After this rigorous reviewing process, five papers were accepted for publication in this special section. All the five papers analyze the application of the intelligent learning systems and algorithms in banking and finance by empirical analysis.

*Guest Editor of the Special Issue of the JILSA "Intelligent Learning Systems in Banking and Finance".
The first paper by V. Pacelli, V. Bevilacqua and M. Azzollini develops and tests empirically an artificial neural network model to forecast the trend of the exchange rate Euro/USD up to three days ahead of last data available. The variable of output of the ANN designed is then the daily exchange rate Euro/Dollar and the frequency of data collection of variables of input and the output is daily. By the analysis of the empirical data, the authors conclude that the ANN model developed can largely predict the trend to three days of exchange rate Euro/USD.

The second paper by B. Alexandrova-Kabadjova, E. Tsang and A. Krause analyses the dynamics of competition in the payment card market through a multi-agent based model, which captures explicitly the commercial transactions at the point of sale between consumers and merchants. Through simulation, the authors attempt to model the demand for payment instruments on both sides of the market. Constrained by this complex demand, a Generalised Population Based Incremental Learning (GPBIL) algorithm is applied to find a profit-maximizing strategy, which in addition has to achieve an average number of card transactions. In this study the authors compare the performance of a profit-maximizing strategies obtained by (GPBIL) algorithm versus the performance of randomly selected strategies. They found that under the search criteria used, GPBIL was capable of improving the price structure and price level over randomly selected strategies.

The third paper by Khaled Assaleh, H. El-Baz and S. Al-Salkhadi presents two prediction models for predicting securities' prices. The first model is developed using back propagation feed forward neural networks. The second model is developed using polynomial classifiers (PC), as a first time application for PC to be used in stock prices prediction. The inputs to both models are identical, and both models are trained and tested on the same data. The study is conducted on Dubai Financial Market as an emerging market and applied to two of the market's lea- 
ding stocks. In general, both models achieved very good results in terms of mean absolute error percentage. Both models show an average error around $1.5 \%$ predicting the next day price, an average error of $2.5 \%$ when predicting second day price, and an average error of $4 \%$ when predicted the third day price.

The fourth paper by M. Gorgoglione and U. Panniello proposes a number of models which can be used to generate marketing actions, and shows how to integrate them into a model embracing both the analytical prediction of customer churn and the generation of retention actions. The benefits and risks associated with each approach are discussed. The paper also describes a case of application of a predictive model of customer churn in a retail bank where the analysts have also generated a set of personalized actions to retain customers by using one of the approaches presented in the paper, namely by adapting a recommender system approach to the retention problem.

The fifth and last paper by V. Pacelli and M. Azzollini develops and tests empirically an artificial neural network model to forecast the credit risk of a panel of Italian manufacturing companies. In a theoretical point of view, this paper introduces a detail literature review on the ap- plication of artificial intelligence systems for credit risk management. In an empirical point of view, this research compares the architecture of the artificial neural network model developed in this research to another one, built for a previous research with a similar panel of companies, showing the differences between the two neural network models.

I would like to thank Professor Stefano Dell'Atti for his guidance in my research activity and for his precious suggestions.

At last, I would like to thank the editor in chief of the JILSA (Xin Xu), my co-editor of this special issue (V. Bevilacqua) and all of the authors (M. Azzollini, V. Bevilacqua, M. Gorgoglione, Hazim El-Baz, B. A. Kapadjova, A. Khaled, E. Krause, V. Pacelli, U. Panniello, E. Tsang, Saeed Al-Salkhadi) and reviewers (E. Angelini, V. Bevilacqua, S. Dell'Atti, A. Malinconico, F. Miglietta, V. Pacelli, S. Sylos Labini) who have made contributions to this special issue.

Vincenzo Pacelli

Guest Editor

JILSA 